\title{
EchoGéo
}

11 | 2010

Madagascar

\section{Reestructuraciones de las periferias hortícolas de Buenos Aires y modelos espaciales ¿ Un archipiélago verde?}

\author{
Julie Le Gall et Matías García
}

\section{CpenEdition}

\section{Journals}

Édition électronique

URL : https://journals.openedition.org/echogeo/11539

DOI : 10.4000/echogeo.11539

ISSN : 1963-1197

Éditeur

Pôle de recherche pour l'organisation et la diffusion de l'information géographique (CNRS UMR 8586)

Référence électronique

Julie Le Gall et Matías García, « Reestructuraciones de las periferias hortícolas de Buenos Aires y modelos espaciales ¿ Un archipiélago verde ? », EchoGéo [En ligne], 11 | 2010, mis en ligne le 24 février 2010, consulté le 31 juillet 2021. URL : http://journals.openedition.org/echogeo/11539; DOI : https:// doi.org/10.4000/echogeo.11539

Ce document a été généré automatiquement le 31 juillet 2021.

EchoGéo est mis à disposition selon les termes de la licence Creative Commons Attribution - Pas d'Utilisation Commerciale - Pas de Modification 4.0 International (CC BY-NC-ND) 


\title{
Reestructuraciones de las periferias hortícolas de Buenos Aires y modelos espaciales ¿ Un archipiélago verde?
}

\author{
Julie Le Gall et Matías García
}

Les auteurs remercient Natalia D'Aquino pour son aimable relecture et les corrections qu'elle a apportées à cet article.

\section{Introducción}

1 Recorriendo las zonas hortícolas de la provincia de Buenos Aires, por ejemplo, en las rutas de La Plata, uno puede ver casas bajas, blancas, rodeadas por un mosaico de rojos, marrones y verdes dado por los cultivos a campo, o iluminadas por los reflejos de luz que transmiten los plásticos de los invernáculos. Sin embargo, los ocupantes de dichas casas ya no son quienes cultivan. Un poco más atrás, encontramos una casilla de madera y nylon o chapa, un horno de barro, ropa secándose y niños jugando en la tierra; es allí donde viven los productores actuales que cultivan el campo y los invernáculos (fotos 1a y b). La mayoría de los productores italianos y portugueses (o descendientes de estos), si bien a menudo continúan viviendo aquí, han dejado la parte productiva a los nuevos horticultores bolivianos o a los hijos de bolivianos. 
Foto 1 a : Periferia de La Plata, AMBA, casa de un ex-productor italiano

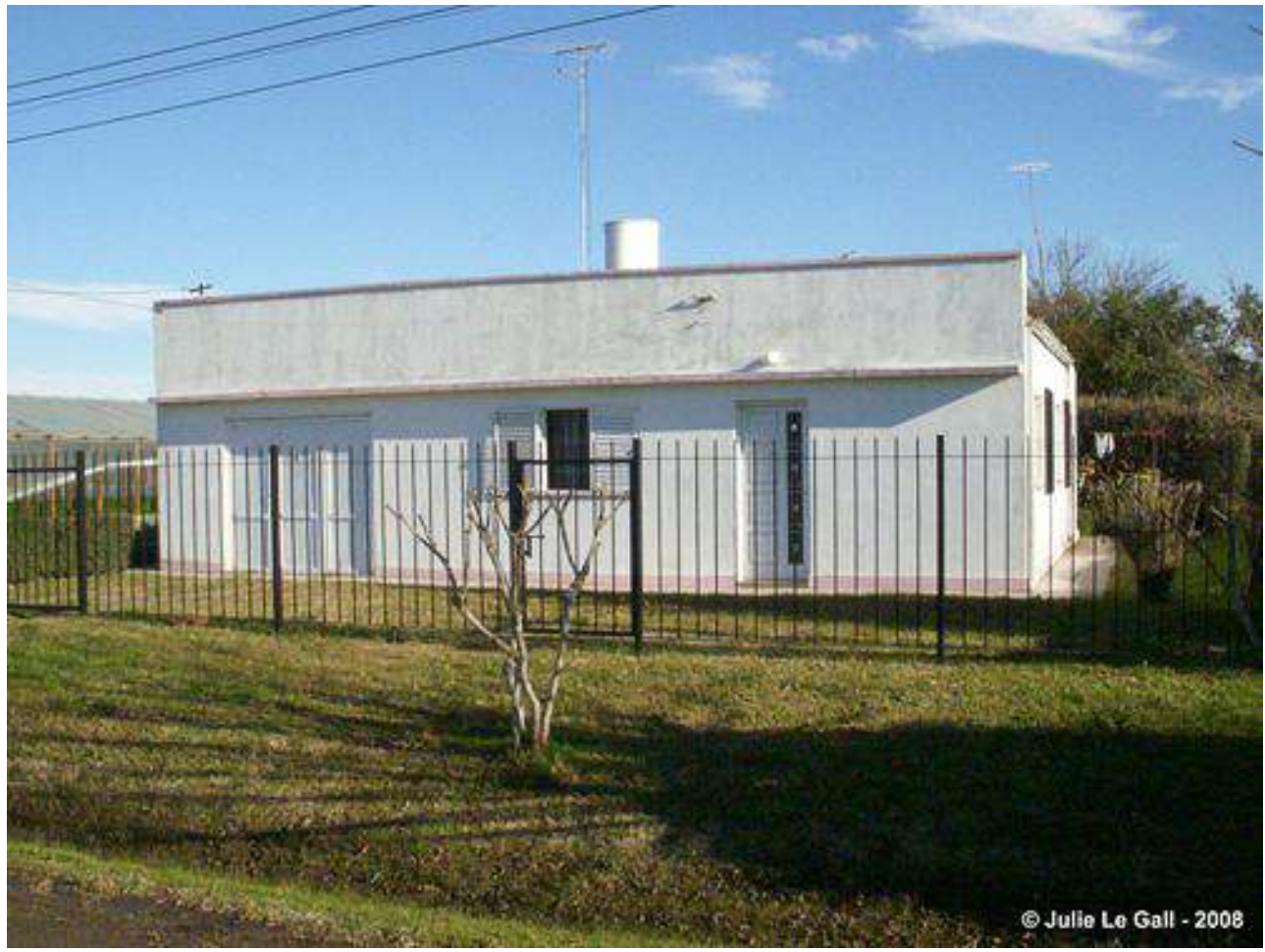

Crédits photo : Julie Le Gall - 2008

Foto $1 \mathrm{~b}$ : Periferia de La Plata, AMBA, casa de un ex-productor boliviano

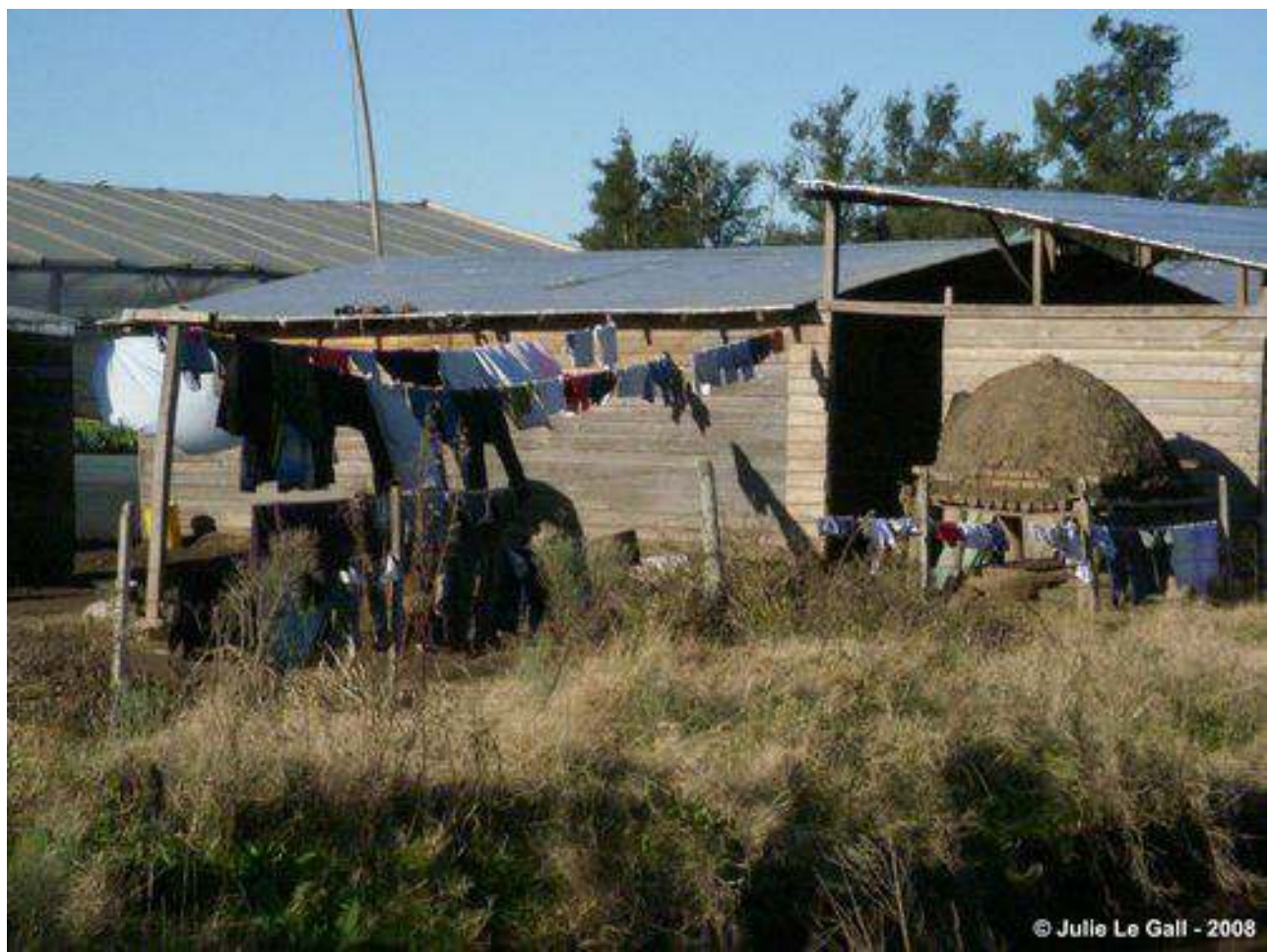

Crédits photo : Julie Le Gall - 2008 
2 Estas imágenes en el paisaje son la parte visible de las transformaciones socioespaciales que está viviendo el sector hortícola argentino en general y, más específicamente, las periferias del Área Metropolitana de Buenos Aires (AMBA) ${ }^{1}$. El AMBA concentra la mayor población del país, con aproximadamente 13 millones de personas, y posee desde su fundación, como toda gran ciudad, una serie de circunferencias productivas agropecuarias que lo abastece. Surge así lo que hasta hoy se denomina "Cinturón Verde Bonaerense", espacio que lo rodea y provee, entre otras, de verduras frescas. La actividad hortícola de Buenos Aires hoy en día tiene la especificidad de estar en manos de los inmigrantes bolivianos y sus descendientes: según el censo hortiflorícola de 2005, alrededor del $25 \%$ de los productores hortícolas eran de nacionalidad boliviana (Ministerio de Asuntos Agrarios y Ministerio de Economía de la Provincia de Buenos Aires, 2006).

3 En el caso particular del AMBA la temática del devenir de los espacios rurales metropolitanos frente a la multiplicación de las presiones que los afectan suscita un doble abordaje. Por un lado, la clara relación con la problemática del ordenamiento territorial de las periferias en un contexto de globalización y metropolización (más desarrollada en la bibliografía de los países del Norte) (Arlaud, et al., 2005, Fleury y Donadieu, 1997). Por otro lado, la reflexión en torno al acceso a los alimentos de una población urbana en un determinado contexto de crisis socio-económica (referenciada por otras metrópolis y ciudades de países en vías de desarrollo) (Chaléard y Dubresson, 1999 ; Douzant-Rosenfeld y Grandjean, 1996). Este trabajo propone captar los procesos de reestructuración que afectan las periferias de Buenos Aires desde los espacios productivos hortícolas enfatizando las sinergias entre lo urbano y lo rural. ¿Cuáles son los factores que llevan a estos procesos? ¿Acaso las prácticas y lógicas del migrante boliviano en el sector hortícola bastan para explicarlos? ¿Qué modelo espacial surge del nuevo panorama regional de la horticultura así esbozado ? Si bien Buenos Aires es percibida como el paradigma de la ciudad latina fragmentada socio y espacialmente (Capron y Thuillier, 2000 ; Prévôt-Schapira, 2002 ; Prévôt-Schapira, 2005; Thuillier, 2006), el hecho de estudiar la metrópolis desde sus periferias agrícolas ¿permitiría proponer otra mirada?

4 Para entender mejor las dinámicas socio-espaciales del AMBA, emerge un enfoque territorial (incluso en los estudios no geográficos) con una doble perspectiva : una local con estudios de casos en determinadas zonas de producción hortícola, y otra regional, tratando de encontrar rasgos comunes en el AMBA. Surge la necesidad de interaccionar entre ambas escalas permanentemente para entender mejor la reestructuración profunda de las áreas hortícolas de los conurbanos bonaerense y platense (Barsky y Vio, 2007 ; Benencia y Quaranta, 2005). Con el objeto de estudiar en profundidad tanto las similitudes como las divergencias del espacio hortícola del AMBA, se tomaron como base de análisis cuali-cuantitativo los partidos de La Plata y Pilar, apoyándose además en entrevistas en profundidad e historias de vida de los productores actuales o pasados. La Plata por ser la región hortícola más importante del CVB, con el mayor número de quintas y superficie hortícola (738 EH y 2.645 has.); mientras que Pilar posee esas características de liderazgo (106 EH y 576 has.), pero sólo en relación a la sección Norte y Oeste del Cinturón (Mapa 2). 
Mapa 1 : Zonas hortícolas bonaerenses y presencia de los productores bolivianos

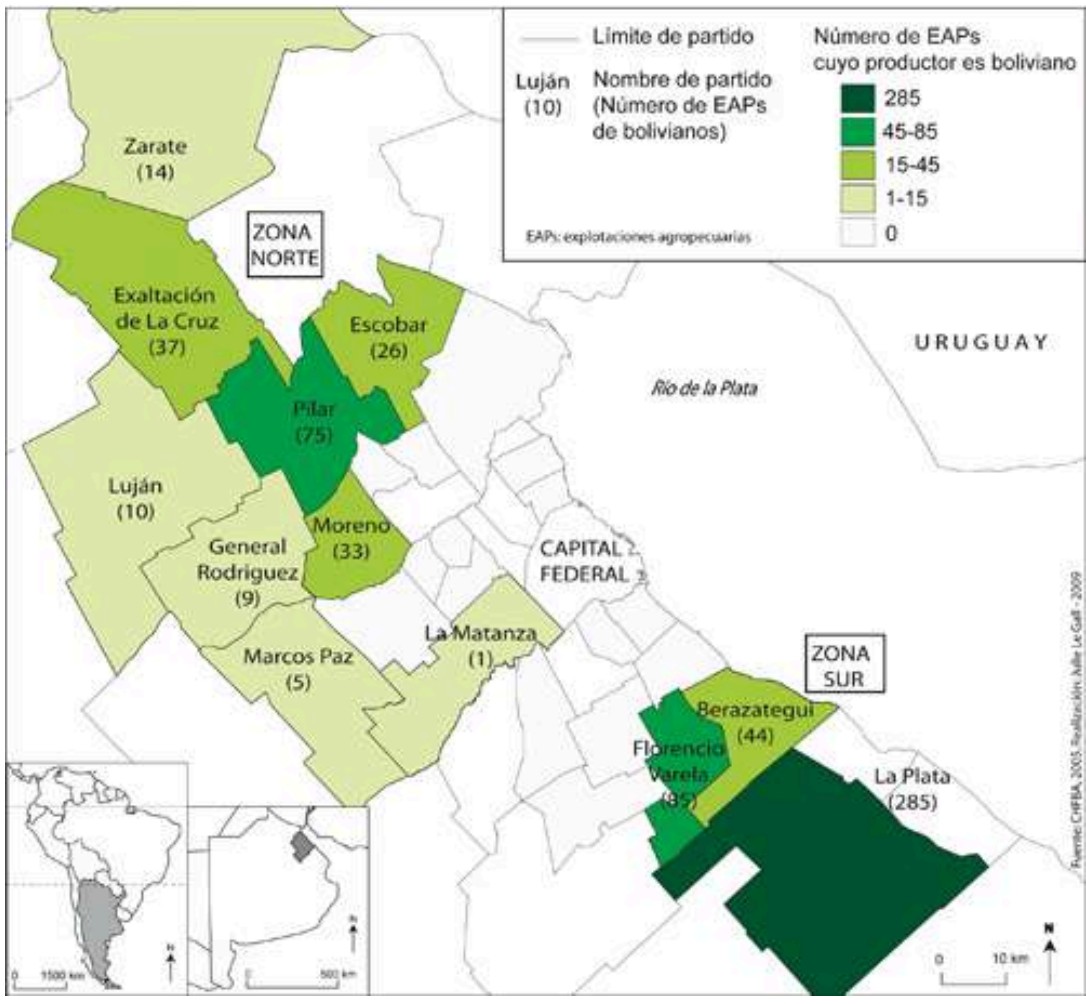

Fuente : CHFBA. Realización : Julie Le Gall, 2009

\section{El Cinturón Verde Bonaerense, un espacio productivo en mano de los migrantes}

5 La particularidad de la actividad hortícola reside en la presencia del migrante como sujeto social preponderante (mano de obra, productor). Asimismo, las transformaciones de las periferias hortícolas de Buenos Aires reflejan tanto la historia migratoria de la Argentina como la participación de los migrantes en las reconfiguraciones territoriales de la metrópolis (Figura 1).

Ya desde mediados del siglo XIX aparecía en los discursos políticos el papel clave del italiano en la actividad agrícola urbana y periurbana para abastecer a la ciudad de Buenos Aires: "Inoltre, il suo compito era quello di soddisfare $i$ bisogni urbani quanto a verdure, ortaggi, cereali ecc." ${ }^{2}$ (Korn, 1987). Y si bien, más tarde, los italianos se destacaron como los pioneros en los cultivos de cereales pampeanos, continuaron hegemonizando la actividad hortícola a lo largo del siglo XX. Otros migrantes, aunque en menor medida, también accedieron a esa actividad: en el caso de la colectividad portuguesa, A. Svetlitza de Nemirovsky (2005: 3) escribe: “...lograron insertarse en el sector industrial y comercial de la economía así como en la producción de verduras, hortalizas y ladrillos." En cuanto a la colectividad japonesa, si bien se la reconoce por su papel en floricultura, había empezado por la horticultura desde la década del 20 y contribuyó a la modernización de la actividad hortícola (Federación de Asociaciones Nikkei en la Argentina, 2004). Las distintas colectividades se asentaron en los "bordes" de los espacios urbanizados (en los alrededores de Capital Federal y La Plata), donde todavía 
se encontraban terrenos para los cultivos. Mientras que los italianos se instalaron en toda la periferia del área urbanizada, los portugueses, por su parte, menos numerosos, se concentraron en las zonas oeste y norte, y los japoneses se ubicaron en colonias agrícolas por la zona de Villa Elisa (Sur) o Escobar y Loma Verde (Norte). En la segunda mitad del siglo XX, se modificó el origen de la migración en la Argentina: las migraciones provenientes de los países limítrofes superaron las de ultramar que predominaban. La figura del migrante boliviano se volvió predominante en la actividad hortícola. Empezaron como peones y algunos lograron ascender en la escala social, pasando por la mediería, la organización de la producción (como arrendatario o propietario) y, a veces, hasta el comercio directo mediante su propio puesto en los mercados mayoristas del AMBA (Benencia, 1997)².

Figura 1 : Historia de las migraciones en Argentina, historia de los horticultores

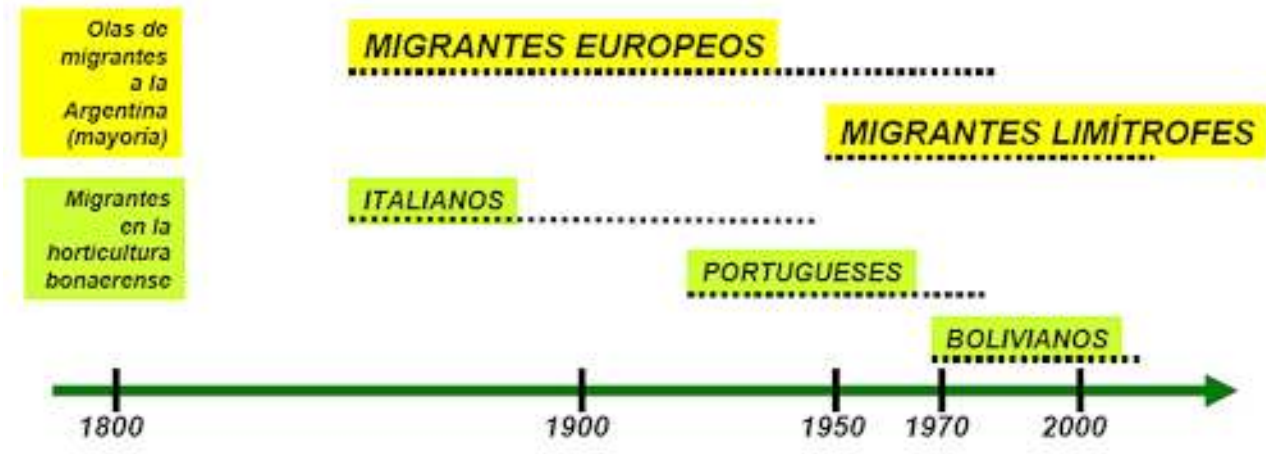

Originariamente, la provisión de verduras estaba a cargo de un conjunto desarticulado de zonas hortícolas localizadas muy cercanas a la urbe o incluso dentro del tejido urbano, como eran los casos de quintas registradas en la zona de Caballito y Flores, o en algunos espacios determinados dentro del casco urbano de la ciudad de La Plata que recién nacía. Con el crecimiento urbano, esas "islas" de producción hortícola se fueron alejando del centro y también se multiplicaron para conformar así un espacio periurbano y continuo de quintas o huertas familiares (Figura 2). Con la llegada de una nueva oleada de inmigrantes europeos tras la $2^{\mathrm{a}}$ Guerra Mundial, surgió un Cinturón Verde que hasta comienzos de la década del 90 presentaba características aparentemente homogéneas. La producción se realizaba a campo, llevada a cabo por familias de inmigrantes italianos (y portugueses en menor medida) y eventuales trabajadores externos. Las quintas eran de mediana superficie (alrededor de 10has), con un manejo y una tecnología uniformes, y cuya producción estaba determinada por las estaciones climáticas (el tipo de hortalizas) y por la superficie disponible (la cantidad de hortalizas). Las verduras se comercializaban principalmente en los mercados mayoristas a través de consignatarios, siendo los habitantes del AMBA los consumidores finales. Durante la segunda mitad del siglo XX, este cinturón se amplió y se desplazó al compás del crecimiento del AMBA y, hacia el final de esta dinámica, a fines de los 90, se comenzaron a evidenciar reestructuraciones socio-espaciales, poniéndose en duda su aparente homogeneidad y continuidad espacial. ¿Existe un vínculo entre la llegada del actor boliviano y este giro espacial? ¿Qué cambios reestructuraron ese "homogéneo" Cinturón Verde Bonaerense? 
Figura 2 : De las islas hortícolas al cinturón verde, crecimiento de Buenos Aires y extensión de las zonas de producción hortícola

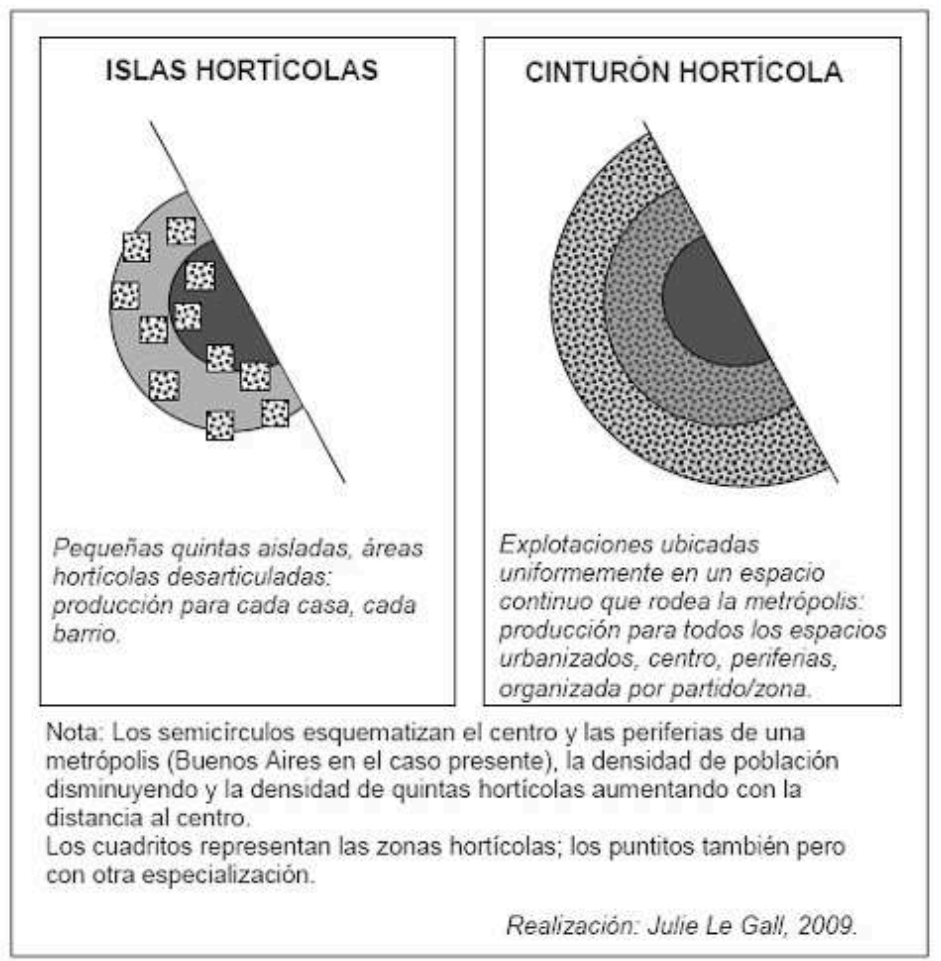

Realización : Julie Le Gall, 2009

\section{Factores externos, mutaciones internas : los orígenes de la diferenciación del CVB}

8 Son pocos los estudios que enfocaron el periurbano bonaerense desde sus lógicas propias : un espacio entre urbe y campo, y un conjunto espacial sometido a variables externas e internas vinculadas a esa doble dimensión ${ }^{4}$. Tanto el contexto económico y político nacional como internacional influyeron sobre la dinámica de la horticultura en las últimas dos décadas cuando la actividad ya se veía afectada por mutaciones internas estructurales. A continuación, a modo de reflexión, proponemos algunos lineamientos.

\section{Factores externos : el contexto argentino}

Las reconfiguraciones territoriales de la horticultura participan de procesos generales y externos al sector. En los últimos 20 años, se evidenció un importante retroceso del Estado como regulador de la actividad económica y cierta recuperación de dicho papel durante la postdevaluación (post-2001). En cuanto a lo económico, mientras que la década del '90 se caracterizó por una apertura económica, una desregulación y un tipo de cambio fijo y bajo, en la postdevaluación, sobresalieron una fuerte devaluación de la moneda y un auge de los precios agrícolas internacionales (por ejemplo, la soja y el trigo), lo que repercutió en la recuperación de la economía argentina. Las políticas migratorias siguieron esa línea hasta 2001, cuando predominaban las amnistías (medidas puntuales delante una situación de hecho) ; sin embargo, a partir de 2001, el 
Estado trató de fomentar una política a mediano plazo, regulando los flujos y la gestión de los migrantes instalados (Programa "Patria Grande").

Estos factores externos al sector tuvieron y tienen múltiples y desiguales influencias a lo largo del Cinturón Verde Bonaerense. El fluctuante contexto económico, el tipo de cambio y la situación del mercado interno repercuten en variables como la tasa de inversión, la producción, la diferenciación por calidad, la expansión y la contracción del sector hortícola, entre otros. Determinan estrategias diferenciadas por los actores de las redes hortícolas (productores, comerciantes, consumidores) que se reflejan en los espacios hortícolas (zonas de producción, mercados mayoristas, tiendas minoristas). Asimismo, estos factores son responsables de una presión por el uso del suelo, altamente marcado por el avance de las urbanizaciones privadas : la fuerte inversión residencial y de recreo en la periferia del AMBA ha sido creciente, con un amesetamiento entre 1998 y 2002 (Barsky y Vio, 2007). También, durante algunas entrevistas con los horticultores, se presintió el avance de la frontera agrícola (el frente soja), que agregaría una presión más sobre sus tierras.

Además, en la actualidad, se observa una nueva mirada política sobre el Cinturón Verde por parte del estado y sus agencias (INTA, Secretaría de Agricultura, Municipios). Tras la devaluación (más precisamente desde 2006), el mayor interés que muestran por los espacios del periurbano es un gran avance. En algunos casos, este interés responde a la necesidad de preservar el uso productivo existente e, incluso, a incentivar el desarrollo de la horticultura. Igualmente, la profundización de políticas migratorias favorece la regularización de la situación de muchos horticultores bolivianos de la región como reconocimiento de su papel fundamental en la actividad. Entre retroceso forzado y fomento de la actividad hortícola, ¿qué diferenciaciones producen estos factores a lo largo del Cinturón Verde?

\section{Mutaciones internas : las crisis de la horticultura bonaerense}

11 Paralelamente, la actividad hortícola se encontró durante este período con mutaciones internas, que potenciaron e interactuaron con los factores externos expuestos up supra.

12 A nivel social, la generación de los "viejos" productores de origen italiano y portugués se enfrentó a una falta de mano de obra y, sobre todo, a que muy pocos de sus hijos quisieron continuar en la actividad, presagiando la vulnerabilidad de dichas quintas. En efecto, el sector venía de sobrepasar tiempos difíciles durante la década del ' 80 , con una crisis originada en una sobreproducción (Benencia, 1997). Los vaivenes del mercado interno impactaron en los establecimientos hortícolas más ineficientes, los que se redujeron hacia fines de la década del '90. Luego, la recesión económica que sufrió el país entre 1998 y 2002 y la posterior reactivación económica y, particularmente, del sector hortícola tuvieron un impacto principalmente en el mercado de hortalizas frescas, por parte de los consumidores, pero más bien por una cuestión de costos de producción (insumos, alquiler, transporte).

El conjunto de esos factores externos (coyunturales) e internos a la horticultura (estructurales) fue causa y consecuencia de los dos cambios mayores de la actividad hortícola: la intensificación y la "bolivianización". Dentro de un contexto social, económico y político favorable, los migrantes bolivianos, ex mano de obra de los viejos productores o los recién llegados que luego de trabajar por sus "paisanos" continuaron 
por su propia cuenta, pudieron insertarse en un nicho económico frágil o vacío. Las nuevas lógicas de producción y comercialización constituyeron oportunidades para los nuevos actores quienes acompañaron el proceso de incorporación tecnológica y modernización de los espacios hortícolas bonaerenses. Sin embargo, cabe destacar que los productores bolivianos, a diferencia de los precedentes actores, si bien son productores principales de las explotaciones hortícolas, no son dueños de la tierra que cultivan : según las estimaciones de un ingeniero agrónomo del INTA ${ }^{5}$, en la zona Norte, solo el $5 \%$ de ellos pudo acceder a la propiedad.

\section{Fronteras rural/urbano y actores : las diferenciaciones del Cinturón Verde Bonaerense}

14 A lo largo de 2000, los factores externos y las mutaciones internas afectan a toda la horticultura del AMBA con desiguales consecuencias y profundizan un proceso de diferenciación en el CVB. A partir de una misma actividad (hortícola), con los mismos actores (mayoritariamente, ex campesinos pauperizados de Bolivia) quienes producen para el mismo mercado (abastecer el AMBA), surgen en diferentes lugares del Cinturón procesos dicotómicos con evoluciones divergentes según cinco variables que se presentan a continuación.

\section{El eje productivo : invernáculo versus campo}

15 El eje productivo se articula con el invernáculo, tecnología que ya dejó de ser homogénea para el Cinturón. Si bien sus primeros intentos se experimentaron en la zona Norte, actualmente allí no hay más de 28 has bajo cubierta sobre el total de la región (5has en Pilar, 10has en Escobar y 13has en Exaltación de la Cruz según el CHFBA '05). Contrariamente, en la zona Sur, y más precisamente en La Plata, las 775has de superficie cubierta dan una media de más de 1 hectárea de invernáculo por explotación (CHFBA'05). El invernáculo es un paquete tecnológico que estructura la organización social y productiva de la quinta. Entre las características más sobresalientes de esta tecnología, se destacan su mayor productividad, lo que repercute en quintas más pequeñas ${ }^{6}$, una diferenciación por la calidad y la obtención de primicias y tardicias. Del otro lado, estas "ventajas" se deben analizar teniendo en cuenta la mayor demanda de mano de obra que esta tecnología implica, como así también su mayor costo (tanto de inversión como de producción). La primera desventaja pudo ser superada en parte por el migrante boliviano, quien dispone para trabajar una numerosa familia y/o paisanos ; la segunda desventaja se convierte en condición limitante para su incorporación, como así también para las inversiones que requiere el acceso al canal de comercialización. Contrariamente, en las quintas del Norte y, en menor medida, del Oeste del CVB, abundan los cultivos a campo perdiendo así su importancia productiva ${ }^{7}$.

\section{El eje comercial : venta directa contra venta en mercados}

16 El eje comercial hace referencia a las diferentes modalidades de comercialización que se observan a lo largo del CVB. Si bien se puede hablar de una introducción en el eslabón de comercialización por parte de los productores (principalmente bolivianos) 
de todo el Cinturón en los últimos 20 años (Benencia y Quaranta, 2005, Le Gall, 2007), se percibe claramente desiguales grados de avances.

La venta directa en quinta es una modalidad que surge hace poco más de 5 años, siendo en la actualidad la más utilizada en la zona de La Plata por pequeños horticultores. La mercadería es comprada por un agente que la transporta hasta un mercado concentrador, en donde se la revende a un puestero o bien la comercializa el mismo, si es que posee un puesto. Esta modalidad posibilita al productor negociar el precio de venta y le permite cobrar en efectivo, a más tardar, al día siguiente de la transacción. Por otra parte, se ajusta bien con productores pequeños y medianos que no tienen suficiente mercadería para llevar al mercado, que no pueden afrontar los servicios de flete o la compra de un vehículo, que eligieron invertir en el eje productivo y/o que carecen de la organización necesaria para poder afrontar el tiempo que implica producir y comercializar en el mercado.

Por otro lado, la venta directa en el mercado es hoy la forma más común de vender en la zona Norte ( $69 \%$ en peso, según el CHFBA'05) y, en menor medida, del Oeste ( $42 \%$ en peso) del Cinturón Verde. Los quinteros comercializan en forma personal su producción en los mercados concentradores, eventualmente complementada con la de otras quintas, en distintos tipos de puestos. Transportan los productos al mercado a través de un vehículo propio (camión, camioneta) o bien en flete. Este sub-canal se podría inferir como un avance más del productor en la cadena de comercialización, en donde supera la instancia de venta en quinta al comercializar directamente con el minorista, apropiándose así del margen de varios intermediarios. (García y al, 2008) El hecho de producir y vender al mismo tiempo constituye una novedad importante en el sistema de comercialización de Buenos Aires, introducida por los migrantes bolivianos. Es, a su vez, el último eslabón antes de la venta directa al consumidor final.

\section{Avance de la urbe : el fenómeno de las urbanizaciones privadas}

En Pilar, el contexto económico post-crisis de 2001 podría haber limitado la ola de inversiones privadas que vivió el partido en la década de los noventa. Pero Barsky (Barsky y Vio, 2007) señala que, si bien "se registró una desaceleración de todos estos intensos fenómenos de reestructuración territorial (...) desde la recuperación de la economía desde fines de 2002 se revirtió el panorama, a tal punto que en la actualidad se habla de un neoboom.". Esos proyectos de rubros diferentes (industriales, tecnológicos, comerciales, inmobiliarios) compiten a nivel espacial con la horticultura. Vidal-Koppman (VidalKoppman) resume el pensamiento de la gran mayoría de los emprendedores privados "quienes opinan que la tierra para usos rurales (aunque tenga una aptitud agrícola excepcional) no es el negocio del momento y que urbanizar para los sectores de mayores recursos sólo acarrea ventajas.". Frente a las manifestaciones espaciales de esas inversiones, el municipio de Pilar puede controlar los usos del suelo y planificar una zonificación que favorezca (o no) a los espacios hortícolas. Sin embargo, en una entrevista en julio de 2008, el subsecretario de medio-ambiente del municipio dijo que "la batalla en Pilar sobre los usos de suelos ya estaba perdida.", y en otra, el Cónsul de Bolivia en la Argentina señaló : "En Pilar, ya está, ya fue." Si bien ningún productor entrevistado ha dicho ser desalojado por un country, la observación del paisaje periurbano habla por sí sólo. La foto 2 muestra el contraste y los procesos en puja que están ocurriendo en dicho territorio. La misma simboliza e ilustra la yuxtaposición de poblaciones y actividades socioeconómicas 
distintas y recuerda que la permanencia de estos intersticios agrícolas no está garantizada.

Foto 2 : Urbanizaciones cerradas y horticultura : la competencia por el espacio. En el fondo, el Country La Cascada ; delante, cultivos de hojas a campo y mujer boliviana sacando la maleza, Pilar.

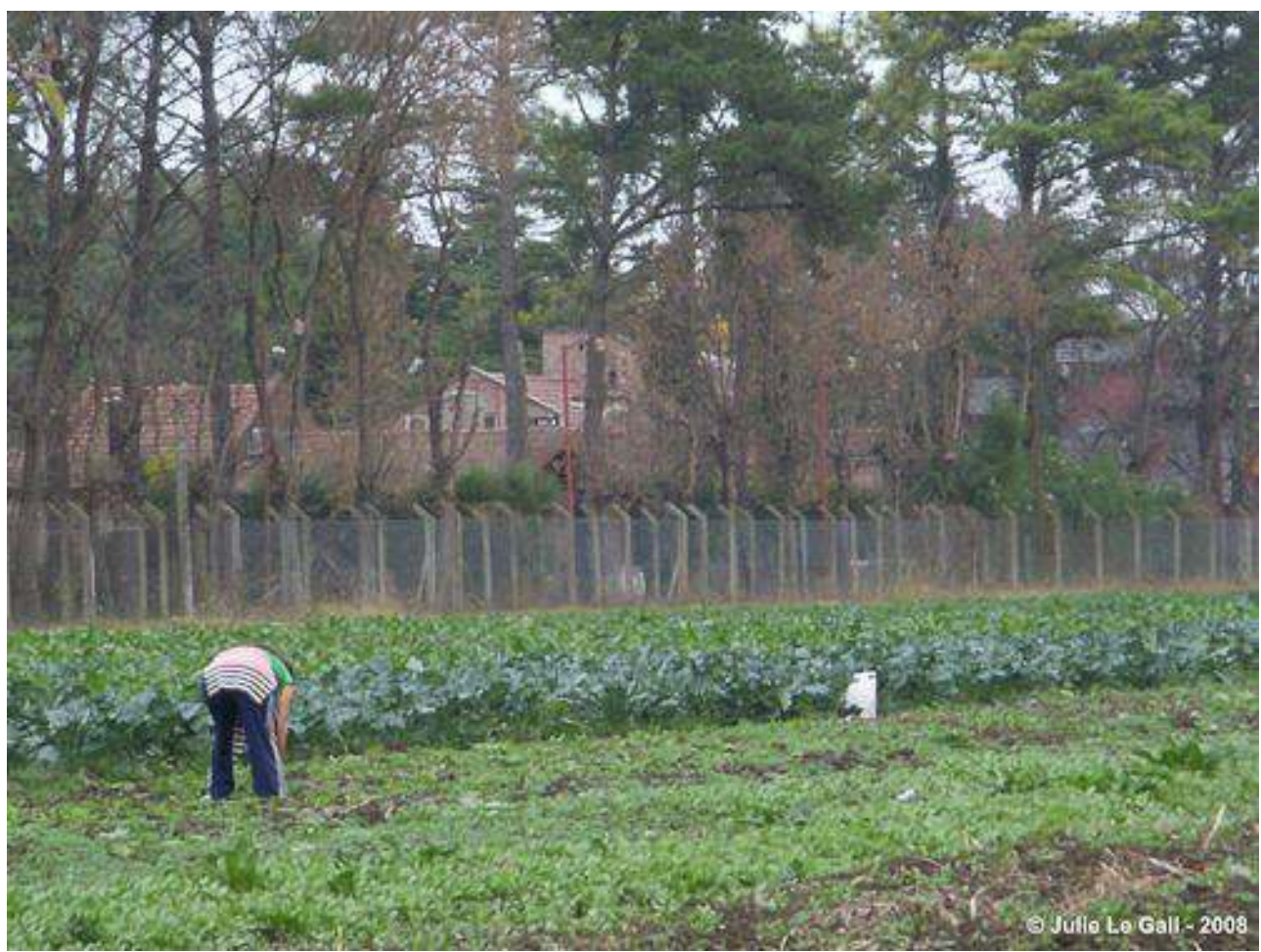

Crédits photo : Julie Le Gall - 2008

Diferente situación se vive en la zona Sur. Los espacios de recreo y urbanizaciones cerradas en La Plata se ubican, coincidentemente con los de la ciudad de Buenos Aires, en la zona Norte del partido (Ringuelet, et al., 2006 ; Torres, 2001). El aglomerado y la disputa de la tierra no afectan la zona típica hortícola platense que se abre en abanico en dirección Sudoeste. Esto se debe a que en La Plata existe hace ya muchos años (e independientemente del intendente de turno), el respeto por una ordenanza municipal que impide la instalación de emprendimientos urbanísticos (léase clubes de campo y barrios privados / countries) en áreas rurales ${ }^{8}$.

\section{¿El avance de la soja?}

De la misma forma que existe una presión "urbana" sobre una parte del Cinturón Verde, también existe el mismo efecto, pero en dirección contraria desde la "frontera agrícola" hacia los espacios periurbanos hortícolas, generando un efecto de "compresión". En este último caso, el responsable sería la soja y su alta rentabilidad postdevaluación, debido no sólo al tipo de cambio que favorece los productos de exportación, sino también a los precios internacionales más altos. Se propone esa dinámica espacial a modo de hipótesis, ya que no todos los productores la validaron y que los precios internacionales cambian las perspectivas de una temporada a la otra.

La soja avanzó sobre espacios que nadie hubiese imaginado, en zonas de parcelas más chicas que en el resto de la Pampa Húmeda y/o imbricadas entre otros usos de suelos, 
que parecían inadecuadas para el empleo de las maquinarias agrícolas. Sin embargo, la rentabilidad de la oleaginosa hizo viable su avance. Los productores bolivianos del partido de Pilar sufren ese progreso al ser mayoritariamente arrendatarios. Para un dueño de campo del CVB, actualmente es más rentable alquilar una hectárea a un pool de siembra que a un horticultor ya que el primero puede permitirse un alquiler más elevado, a diferencia del pequeño productor. Para el productor, cada mudanza significa nuevas inversiones de tiempo y dinero, por la limpieza del nuevo campo, la perforación para la bomba de agua, la construcción de su casa, etc. En el Norte, los quinteros se van a Los Cardales, Robles, Exaltación de la Cruz, o hasta San Pedro, donde todavía pueden costear los arrendamientos, o bien se dirigen al sur, a La Plata9.

En la región hortícola de La Plata, la soja se encontró con dos tipos de impedimentos : El primero de ellos fue el costo del arrendamiento. Mientras que en la zona Norte del CVB el arrendatario sojero es altamente competitivo frente a los aproximadamente \$100/ mes/ha que pagaban los horticultores, diferente es el panorama del Sur, donde el arrendamiento promedio ronda los $\$ 300 / \mathrm{mes} / \mathrm{ha}$, siendo así aún más caro que el pagado en algunas zonas agrícolas de la región pampeana ${ }^{10}$. El otro impedimento es de orden estructural y está asociado al tipo de tecnología hegemónica en la zona: el invernáculo. Dicho paquete permite un uso más eficiente del suelo, por lo que las quintas son de superficie mucho más reducida que en el Norte. A este obstáculo se le suma la presencia de una estructura de palos y plásticos que eventualmente habría que remover ante la opción de hacer algún cultivo extensivo.

Las tendencias en detrimento de la actividad hortícola son, en la actual coyuntura, la soja y las inversiones urbanísticas. A través de estas variables, se revelan las lógicas internas a cada partido como factores de preservación de los espacios hortícolas : del caso de Pilar hace falta rescatar el rol esencial de la planificación-zonificación que se implemente a nivel del partido y del grado de intervención que los actores públicos establezcan para el uso ordenado del suelo. Se puede afirmar que, debido al avance de las fronteras urbanas y/o agrícolas, la merma en la producción en las zonas hortícolas extra La Plata fortaleció y amplió la actividad productiva en la zona Sur.

\section{Tiempos de boliviano : cuestiones étnicas}

Además de estas cuestiones estructurales y espaciales, los productores bolivianos o hijos de bolivianos entrevistados presentan características distintas que podrían ayudar a explicar las diferenciaciones observadas a lo largo del CVB. Una de las características es el origen en Bolivia. Los horticultores de la zona de Pilar provienen mayormente de Potosí, eventualmente Sucre, mientras que los de La Plata son de Tarija ${ }^{11}$.

En Potosí, los productores eran campesinos cuya producción mayoritaria era de autoconsumo, ya que las tierras no permiten generar excedentes para comercializar. Algunos de ellos trabajaron en las minas. En Tarija, si bien algunos provienen también de regiones serranas donde la producción se ve limitada por cuestiones edáficas e hidrológicas, otros son originarios de la zona "del valle" donde se producen frutas, hortalizas y papas, tanto para el consumo como para vender en los mercados. Ambos grupos de migrantes poseen algún tipo de experiencia en la producción agrícola, aunque prácticamente hayan aprendido la horticultura comercial en la Argentina. La cuestión étnica podría tener algún peso en el comportamiento comercial diferencial 
que muestran los potosinos en el Norte del CVB : su experiencia en la mina es una de las hipótesis para explicar su mayor tendencia a conformar asociaciones y cooperativas ${ }^{12}$.

Tal vez de mayor significación resulte que mientras que los migrantes de Potosí arribaron a Pilar y Escobar en la década del '80, los de Tarija llegaron a La Plata recién a mediados de los '90, e incluso, algunos en 2004-2005. El mayor tiempo de arraigo de los bolivianos en el Norte del Cinturón habría fomentado un grado de desarrollo del enclave étnico superior que les permitió un prematuro y/o mayor desarrollo en el eslabón comercial. Contrariamente, en la parte Sur del CVB, el acceso a la tierra ha ocurrido en un período de tiempo significativamente menor en relación al Norte. Esto podría explicarse a través de la coincidencia del arribo de dichos migrantes con un período de alta permeabilidad social (crisis y postdevaluación).

La figura 3 retoma la noción de factores externos / mutaciones internas en la horticultura y las diferentes variables con el ejemplo de la presión sobre la tierra en Pilar. Sin ser exhaustivos, los factores permiten poner en evidencia cómo dos situaciones que se dan hoy en día en la horticultura tienen consecuencias diferentes a lo largo del CVB. Constituye una propuesta de esquema para profundizar aún más el proceso de construcción y reconstrucción territorial de la horticultura en el AMBA.

Figura 3 : Dinámica de los espacios hortícolas, causas y consecuencias : el ejemplo de la zona Norte

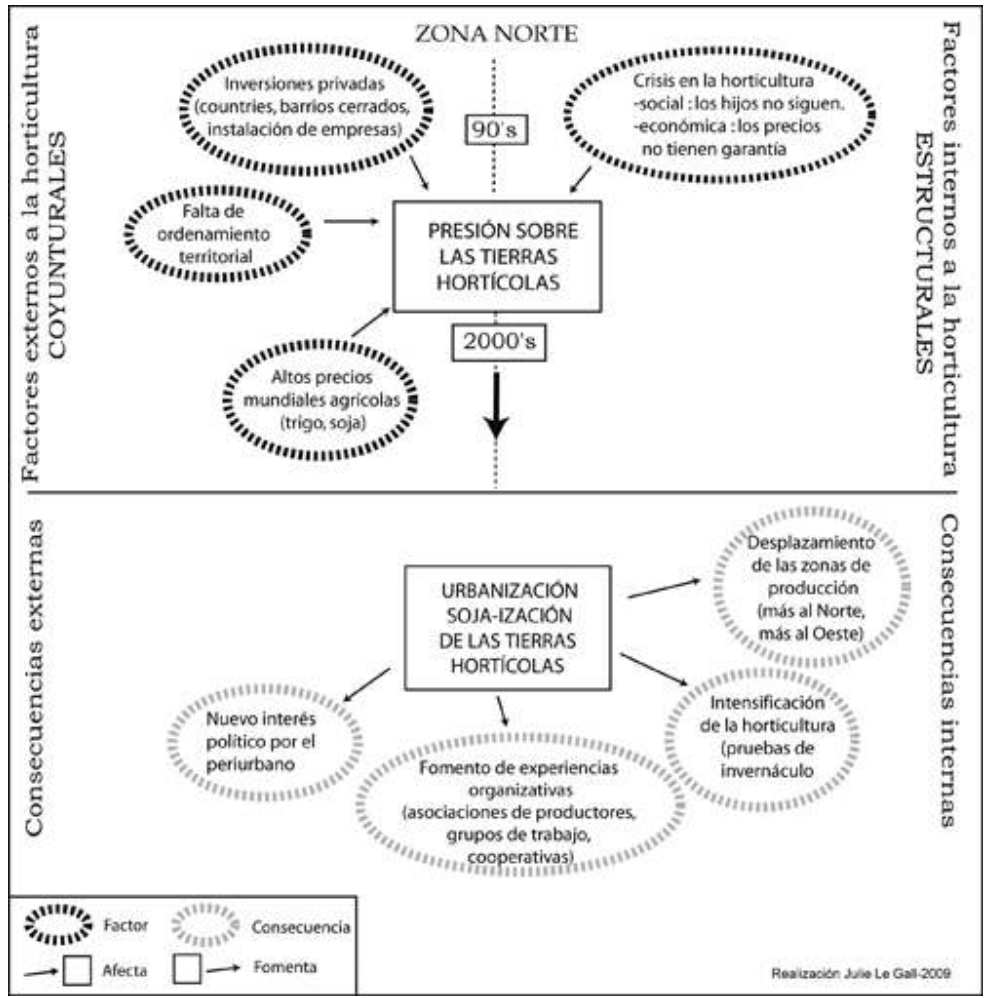

Realización : Julie Le Gall, 2009

A modo de resumen, se propone el cuadro comparativo de las tendencias en las zonas Norte y Sur. 
Cuadro 1 : Zona Sur, Zona Norte, del periurbano bonaerense : tendencias de diferenciación

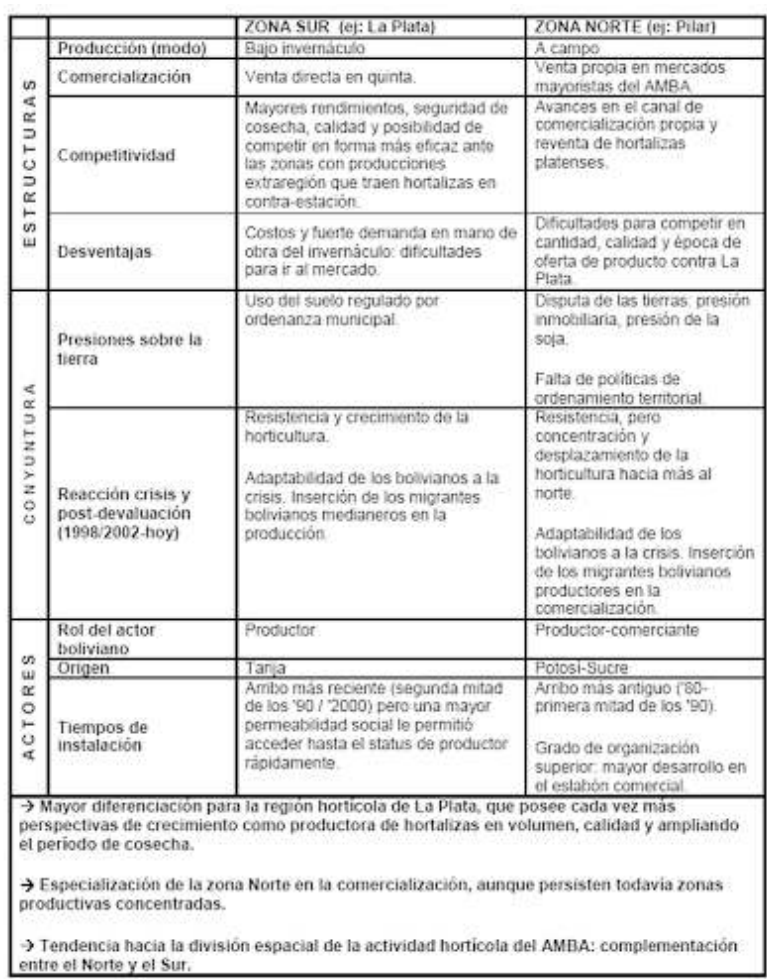

30 Se evidenció con claridad un proceso de diferenciación de los espacios hortícolas del AMBA por cuestiones étnicas, tecnológicas, estructurales y políticas (internacionales, nacionales y municipales). Al efecto de ampliación o corrimiento de las redes de abastecimiento hacia el tercer y casi cuarto cordón de Buenos Aires, acompañó una tendencia de concentración de la actividad en ciertas zonas que dificulta y hasta impide la representación de un cinturón continuo de producción hortícola que rodee el AMBA. Emergen zonas hortícolas especializadas : ¿Funcionan las zonas Sur y Norte como dos nuevas islas de abastecimiento del AMBA como las que originalmente abastecían de hortalizas la ciudad durante la primera mitad del siglo XX ?

\section{Conclusiones : ¿Hacia un archipiélago verde?}

Las dos modalidades de venta en la zona Norte y Sur muestran diferenciación, pero también complementación. Con esto último se hace referencia a la compra por parte de productores-comerciantes del Norte de hortalizas en quintas de productores de la zona Sur, abasteciéndose así de productos en cantidad y calidad que no siempre pueden garantizar. Por otra parte, esta mayor propensión a comercializar en la zona Norte tiene como causa-consecuencia la existencia de un gran número de mercados en la zona Norte y Oeste del CVB, lo que posibilita y estimula esta comercialización lo que marca a su vez un nuevo contraste con la región Sur. A nivel territorial, la existencia de una red de mercados en la zona Norte modifica tanto las relaciones entre el Norte y el Sur como las áreas de distribución de las distintas zonas hortícolas. Lejos de dividir el periurbano, esas tendencias crean un tejido denso y renovado de redes atravesando las periferias del AMBA. Estas redes se apoyan directamente en las redes sociales de los bolivianos: entre familiares y originarios de un mismo pueblo en Bolivia impusieron su presencia 
en todos los eslabones de la cadena hortícola. Los contactos entre "paisanos" facilitaron la entrada de sus productos en los diferentes mercados (entre quinteros, transportistas y puesteros), tal como la circulación entre los espacios de producción y los de comercialización.

El intercambio de mercaderías producidas en el Sur y comercializadas por productores de la zona Norte y la presencia de bolivianos vinculados en ambas zonas muestran que si bien cada "isla verde" tiene su particularidad, están articuladas entre sí y funcionan en interrelación y complementariedad. Convocar la figura del archipiélago destacaría justamente la necesaria continuidad más que las rupturas (Arrault, 2005). Hablar de un "Archipiélago Hortícola" (Le Gall, 2008) pone en evidencia las reestructuraciones de los espacios hortícolas del AMBA y dibuja otra cara de la metrópolis de Buenos Aires, más articulada que fragmentada. Mientras que en el proceso de conformación del CVB tuvo gran influencia el horticultor italiano, en los actuales "tiempos de boliviano", resulta ineludible destacar el rol de este migrante limítrofe en la ruptura y consolidación del “archipiélago verde". En Buenos Aires, este nuevo modelo permite pensar el vínculo entre las redes sociales de inmigrantes y la emergencia de nuevas redes metropolitanas.

Figura 4 : Un nuevo modelo de la horticultura bonaerense : el archipiélago hortícola

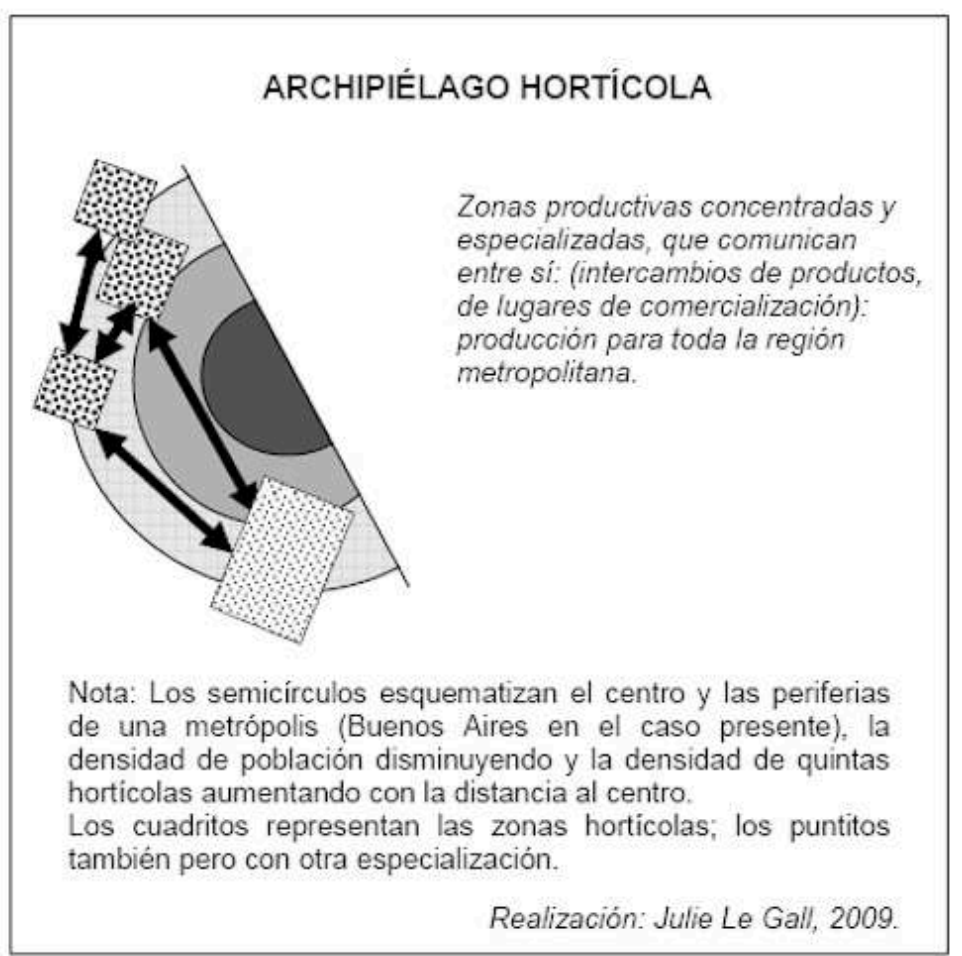

Realización : Julie Le Gall, 2009 


\section{BIBLIOGRAPHIE}

Arlaud S., Jean Y., Royoux D. (Eds), 2005. Rural/urbain, nouveaux lieux, nouvelles frontières. Rennes, Presses Universitaires de Rennes, 506 p.

Arrault J.-B., 2005. Du toponyme au concept ? Usages et significations du terme archipel en géographie et dans les sciences sociales. L'Espace géographique, nº4, p.315-328.

Barsky A., Vio M., 2007. "La problemática del ordenamiento territorial en cinturones verdes periurbanos sometidos a procesos de valorización inmobiliaria. El caso del partido del Pilar, Región metropolitana de Buenos Aires." Communication lors de IX Coloquio internacional de geocrítica, Porto Alegre.

Benencia R. (Eds), 1997. Área Hortícola Bonaerense - Cambios en la producción y su incidencia en los sectores sociales. Buenos Aires (Argentine), La Colmena, 279 p.

Benencia R., 1997. De peones a patrones quinteros. Movilidad social de familias bolivianas en la perifería bonaerense. Estudios migratorios latinoamericanos, nº35, p.63-101.

Benencia R., Quaranta G., 2005. Producción, trabajo y nacionalidad: configuraciones territoriales de la producción hortícola del cinturón verde bonaerense. Revista interdisciplinaria de Estudios Agrarios, ํㅡㄹ, p.101-132.

Capron G., Thuillier G., 2000. Buenos Aires, de la métropole européenne à la mégapole latinoaméricaine, in Capron G., Thuillier G., Buenos Aires, de la métropole européenne à la mégapole latinoaméricaine. Toulouse, Presses Universitaires du Mirail, p.116-134.

Chaléard J.-L., Dubresson A., 1999. Villes et campagnes dans les pays du Sud. Géographie des relations. Paris, Karthala, 258 p.

Douzant-Rosenfeld D., Grandjean P. (Eds), 1996. Nourrir les métropoles d'Amérique latine. Paris, L'Harmattan, $302 \mathrm{p}$.

Federación de Asociaciones Nikkei en la Argentina, 2004. Historia del Inmigrante Japonés en la Argentina: Período de Preguerra. Buenos Aires, 400 p.

Fleury A., Donadieu P., 1997. De l'agriculture périurbaine à l'agriculture urbaine. Le Courrier de l'environnement, $\mathrm{n} \div 31$.

Korn F. (Eds), 1987. La populazione di origene italiana in Argentina. Turin, Fondazione Giovanni Agnelli, 613 p.

Le Gall J., 2007. "Quand les migrants construisent des territoires : Le marché de gros de la Matanza, nouveau territoire bolivien de Buenos Aires". Communication lors de Second Congrès bisannuel du GIS Amérique latine, Rennes.

Le Gall J., 2008. "Horticultura y bolivianos en el espacio metropolitano bonaerense: nuevos actores, nuevos territorios, nuevas articulaciones". Communication lors de Congreso Nacional de Geografía, 69 Semana de Geografía: "Geografía y sostenibilidad territorial", Buenos Aires.

Ministerio de Asuntos Agrarios y Ministerio de Economía de la Provincia de Buenos Aires, 2006. Censo Hortiflorícola de Buenos Aires 2005 (CHFBA'05). La Plata, 116 p.

Pizarro C., 2009. "Olor a negro. Discurso, discriminación y segmentación étnica en el lugar de trabajo. " Communication lors de IV Coloquio de investigadores en estudios del discurso, Córdoba. 
Prévôt-Schapira M.-F., 2001. Buenos Aires, métropolisation et nouvel ordre politique. Hérodote, nº101, p.122-152.

Prévôt-Schapira M.-F., 2002. Buenos Aires, entre fragmentation sociale et fragmentation spatiale, in Prévôt-Schapira M.-F., Buenos Aires, entre fragmentation sociale et fragmentation spatiale. Paris, L'Harmattan, Coll. Villes et entreprises, p.195-208.

Prévôt-Schapira M.-F., 2005. De l'usage de la fragmentation urbaine en Amérique latine (vue de Buenos Aires), in Prévôt-Schapira M.-F., De l'usage de la fragmentation urbaine en Amérique latine (vue de Buenos Aires). Paris, p.483-495.

Rhein B., Elissalde B., 2004. La fragmentation sociale et urbaine en débats. L'Information Géographique, ํํ2, p.115-126.

Ringuelet R., Cavicio R., Simonatto S., 2006. "Trama política, formas organizativas y desarrollo local en el mundo rural periurbano del Gran Buenos Aires. " Communication lors de Associação Latinoamericana de Sociología Rural (ALASRU) VII Congreso Latino-Americano de Sociología Rural, Quito, Ecuador.

Thuillier G., 2006. Les quartiers enclos à Buenos Aires : la ville privatisée ? Géocarrefour, 81, ㄲo2, p. 151-158.

Torres H., 2001. Cambios socioterritoriales en Buenos Aires durante la década de 1990. EURE, 27, $\mathrm{n} \div 80$, p.33-56.

Vidal-Koppman S., 2006. La articulación global-local o cuando los actores privados construyen una nueva ciudad. Scripta Nova. Revista electrónica de geografía y ciencias sociales , 10, n²18.

Disponible à l'adresse : http://www.ub.es/geocrit/sn/sn-218-39.htm. Consulté en Juillet 2008.

\section{NOTES}

1. El espacio regional del AMBA incluye la Ciudad de Buenos Aires, los partidos del Gran Buenos Aires, el Gran La Plata y una serie de localidades del tercer cordón como Escobar, Cañuelas, General Rodríguez, Marcos Paz, Pilar y San Vicente, que suman en total 34 partidos. El uso ha impuesto la denominación de "primer cordón " a una superficie semicircular alrededor de la Capital que se extiende hasta aproximadamente $25 \mathrm{Km}$. del centro (y que incorpora los municipios de la Provincia de Buenos Aires colindantes con la Capital Federal); se denomina "segundo cordón" al semicírculo subsiguiente, que se extiende hasta aproximadamente 40 ó 50 Km. del centro y, finalmente, el más reciente "tercer cordón", que se extiende (con fluctuaciones) desde aproximadamente los $40 \mathrm{Km}$. y avanza de manera rápida y consistente, en particular durante los últimos años (Torres, 2001).

2. "Por otra parte, su tarea era satisfacer las necesidades urbanas en verduras, legumbres, cereales, etc..."

3. Otros, empezaron con la venta callejera en el centro de la ciudad, para luego tener una verdulería e incluso, a veces, alcanzar un puesto en los mercados.

4. Los autores que analizaron los procesos de metropolización y fragmentación desde una perspectiva urbana destacaron el rol de las políticas tanto municipales como nacionales e internacionales en estos procesos (Prévôt-Schapira, 2001).

5. Instituto Nacional de Tecnologías Agropecuarias.

6. La casi total ausencia de invernáculos en Pilar responde a la presencia de quintas con una superficie de casi un $50 \%$ mayor que en el Sur.

7. Según el CHFBA'05, mientras que Pilar produce 9.056Tn de hortalizas al año, La Plata supera las 76.000Tn. 
8. Se trata de la Ordenanza Municipal № 9.231/00, la cual tiene como antecedente la ordenanza № 4495 del año 1978 y en lo sucesivo modificada por las ordenanzas 9380/01, 9664/03 y 9878/04. El art. 268 regula los usos admitidos para el Área Rural-Zona Rural Intensiva, definidos como "sectores pertenecientes o próximos al cinturón verde platense". Concretamente se declara dicha área como "...de protección para el uso hortícola y por lo tanto se prohíben nuevos usos que no se correspondan con las actividades agrícola, hortícola y servicios asociados a ella...”. Con ello se busca "...la consolidación de su perfil productivo promoviendo el uso intensivo del suelo con actividades de tipo agrícola".

9. Se puede suponer que esa presión ocurre no sólo en gran parte del CVB, sino también, y con mayor intensidad aún, en otras regiones hortícolas similares, como los Cinturones Verdes de Rosario, Santa Fe y Córdoba, entre otros.

10. Estimación para las campañas 2004-2008.

11. Esta particular distribución espacial obedece, entre otras lógicas, a las redes de territorios que tejen los migrantes entre el allá y el acá (instalación en el espacio receptor). Según su capital (social, económico), el migrante elige un espacio donde llegar. Así, puede ser una casa de familiares o de conocidos, lo que explica que se juntan los de Potosí en alguna región y los de Tarija en otra.

12. También se debe tener en cuenta las discriminaciones vividas por los bolivianos para explicar su mayor agrupación (en Escobar, por ejemplo) (Pizarro, 2009).

\section{RÉSUMÉS}

L'article analyse la structure socio-productive des périphéries maraîchères de l'Aire métropolitaine de Buenos Aires (AMBA), leur évolution durant ces cinquante dernières années, et le rôle des migrants Boliviens dans les recompositions spatiales qui les affectent. Dans un contexte d'influences externes et internes à l'activité maraîchère (conjoncturelles et structurelles), on a sélectionné une série de variables (production, commercialisation, avancées des fronts urbain et agricole, caractéristiques des migrants) qui expliquent les processus de concentration et de différenciation des espaces maraîchers de Buenos Aires. Est mis en évidence le développement inégal de la région Nord (Pilar) et Sud (La Plata), qui bouscule le modèle de ceinture verte continu et uniforme prédominant jusqu'alors pour décrire les périphéries maraîchères. Devant l'apparition de deux grandes «îles » productives, on privilégie la figure "d'archipel maraîcher»: elle révèle les complémentarités émergentes entre régions Nord et Sud, notamment sous l'influence des migrants boliviens et de leurs réseaux, et les recompositions métropolitaines à l'œuvre.

El presente trabajo analiza la actual estructura socioproductiva de las periferias hortícolas del Área Metropolitana de Buenos Aires (AMBA), su evolución en los últimos cincuenta años y el papel que jugaron los migrantes bolivianos en sus recomposiciones socio-espaciales. En el marco de una serie de cambios políticos, económicos, migratorios y de avance de la frontera agrícola y urbana, se seleccionaron un conjunto de factores claves para el sector hortícola, especialmente en la región norte (Pilar) y sur (La Plata) del AMBA. Se evidencia una fuerte tendencia hacia la diferenciación espacial y el desarrollo desigual en el interior del AMBA así como también un quiebre en un área que ahora se puede señalar como heterogénea. La estructura diferenciada actual del área se profundizaría tanto por las evoluciones disímiles de los partidos como por las 
características de los migrantes, lo que no impediría nuevas articulaciones y dibuja así un archipiélago hortícola.

\section{INDEX}

Palabras claves : bolivianos, Buenos Aires, horticultura, periurbano, redes

Mots-clés : Boliviens, Buenos Aires, maraîchage, périurbain, réseaux migratoires

\section{AUTEURS}

\section{JULIE LE GALL}

Julie Le Gall est doctorante en géographie, UMR 8586 CNRS-PRODIG, sous la direction du Pr. JeanLouis Chaléard et de la Dr. Susana M. Sassone, ATER à l'Université Paris 1 PanthéonSorbonne.julielegall@gmail.com

\section{MATÍAS GARCÍA}

Matías García est ingénieur agronome, doctorant en sciences sociales, FLACSO Buenos Aires, sous la direction de R. Benencia, boursier du CONICET et enseigne à l'Université nationale de la Plata (Argentine).garciamatias@agro.unlp.edu.ar 